\title{
Oxford Textbook of Paediatric Pain: Patrick J. McGrath, Bonnie J. Stevens, Suellen M. Walker, William T. Zempsky (eds)
}

\author{
Published by Oxford University Press, Oxford, United Kingdom, \\ ISBN: 978-0-19-964265-6, First Edition: 2014; Pages: 687
}

Jayashree Sood

Received: 24 April 2014 / Accepted: 19 May 2014 / Published online: 5 June 2014

(C) Dr. K C Chaudhuri Foundation 2014

Pain is a complex phenomenon which is even more challenging to manage in the paediatric population. There are very few books which have elaborated on pain management in the pediatric age group.

The Oxford Textbook of Paediatric Pain is a concise textbook which covers all aspects of pain in this subset of patients. The editors of this book are specialists in pediatrics and pain management. The editor (PJM) has published several books on pain management in infants and children and this book is another useful addition. The contributors of the book are an international faculty from various specialties. They include anesthesiologists, pediatricians, psychologists, psychiatrists, neuroscientists, pain therapists and rheumatologists.

The book has 687 pages with 65 chapters divided into 9 Sections.

The 'Introduction' in Section-1 deals with history, prevalence and long term effects of pain in the pediatric population. The authors have very explicitly started with the history of 'anesthesia', and how 'pain relief' was actually achieved due to advancement in anesthetic drugs and techniques.

Section-2 covers the biological basis of pediatric pain including nociceptive and antinociceptive pathways. The social and psychological basis of pediatric pain is well written and covered in detail in Section-3.

Section-4 deals extensively with painful conditions and their management in specific populations, including children with developmental disabilities and those with arthritis and arthropathy. This Section has 19 chapters and includes

\footnotetext{
J. Sood $(\bowtie)$

Department of Anesthesiology, Pain and Perioperative Medicine,

Sir Ganga Ram Hospital, New Delhi 110060, India

e-mail: jayashreesood@hotmail.com
}

important topics like chronic pelvic pain and pain associated with sickle cell disease and cancer.

While the pharmacotherapeutic options for cancer pain relief are written in details, there is no mention of the drug dosage. If 'Oxford Textbook of Paediatric Pain' has to be a reference book for the pain specialist, it would have been appropriate to include the doses of the drugs as well.

Description of the PCA pump along with photographs would have completed the methods of administering analgesia in the postoperative period. An example, with photograph, of any regional block performed commonly under ultrasound guidance should have been included as well.

Assessment of painful conditions is described in Section-5. Pharmacological interventions, which are the backbone of pain management, are written in Section-6.

The book would have been more appealing if photographs had been included in the chapter on interventional techniques.

Information and communication technologies including internet based chronic pain management have been elaborately written in Section-7. Other chapters in this Section include the psychosocial interventions utilized in pain management. Section-8 includes various physical interventions used for pain relief.

Key recommendations should have been written at the end of each chapter, to help the reader get an overview of the chapter.

Case examples which have been cited in most of the chapters are practical oriented and have made the reading more interesting.

Overall a well written book.

I am sure this book will find a place on the bookshelves of many physicians interested in pain management. I highly recommend this book for the libraries of institutions which have a dedicated pediatric department and 'pain management services' in their hospital. 